\title{
Fixed points for mappings defined on pseudometric spaces
}

\author{
MitrofAn M. CHOBAN
}

\section{ABSTRACT.}

In this article, the distinct classes of continuous pseudometrics and metrics (perfect, quasi-perfect, sequentially complete pseudometrics and metrics) are defined and studied in depth. The conditions under which the set of fixed points of a given mapping of a space with concrete pseudometric is non-empty are determined. Some examples are proposed. For spaces with pseudometrics there are proved the Bishop-Phelps, Takahashi, Caristy and other theorems.

\section{REFERENCES}

[1] Antonovskii, M. Ja., Boltjanskii, V. G. and Sarymsakov, T. A., A survey of the theory of topological semifields, Uspehi Mat. Nauk, 21 (1966), No. 4 , 185-218 (English translation: Russian Math. Surveys, 21 (1966), No. 4, 163-192)

[2] Arhangel'skii, A. V., A class of spaces which contains all metric and all locally compact spaces, Matem. Sb., 67 (1965), 55-88 (English translation: Amer. Math. Soc. Transl., 92 (1970), 1-39)

[3] Arhangel'skii, A. V., Mappings and spaces, Uspehy Matem. Nauk, 21 (1966), No. 4, 133-184 (English translation: Russian Math. Surveys, 21 (1966), No. 4, 115-162)

[4] Berinde, V., Generalized contractions in $\sigma$-complete vector lattices, Univ. u Novom Sadu, Zb. Rad. Prirod.-Mat. Fak. Ser. Mat., 24 (1994), No. 2, 31-38

[5] Caristi, J, , Fixed point theorems for mappings satisfying inwardness conditions, Trans. Amer. Math. Soc., 215 (1976), 241-251

[6] Cauty, R., Solution du probléme de point fixe de Schauder, Fund. Math., 170 (2001), 231-246

[7] Choban, M., The open mappings and spaces, Supl. Rend. Circolo Matem. di Palermo., Serie II, (1992), No. 29, 51-104

[8] Choban, M. M. and Calmutchi, L. I., Fixed points theorems in multi-metric spaces, Annals of the Academy of Romanian Scientists, Series on Mathematics and its Applications, 3 (2011), No. 1, 46-68

[9] Choban, M. M. and Calmutchi, L. I., Fixed points theorems in E-metric spaces, ROMAI Journal, 6 (2010), No. 2, 83-91

[10] Engelking, R General Topology, PWN, Warszawa, 1977

[11] Gelfand, I. M., Raikov, D. A., and Shilov, G. E., Commutative normed rings, Gos. Izd. Fiz.-Matem. Lit., Moskva, 1960 (English translation: Chelsea Publishing Co., New York, 1964)

[12] Granas, A., and Dugundji, J., Fixed point theory, Springer-Verlag, New York, 2003

[13] Iseki, K., On a Banach theorem on contractive mappings, Proceed. Japan Academy, 41 (1965), 145-146

[14] Kopperman, R., All topologies come from generalized metrics, American Math. Monthly, 95 (1988), No. 2, 89-97

[15] Krötzsch, M., Generalized ultrametric spaces in quantitative domain theory, Theoretical Computer Science, 368 (2006), No. 1-2, 30-49

[16] Morita, K., A survey of the theory of M-spaces, General Topol. Appl., 1 (1971), 49-55

[17] Nedev, S. I. and Choban, M. M., A general concept of metrizability for topological spaces, Annuare Univers. Sofia, Facult. Math., 65 (1973), 111-165

[18] Rus, I. A., Petrusel, A., and Petrusel, G., Fixed point theory, Cluj University Press, Cluj-Napoca, 2008

[19] Smyth, M. B., Topology, In: Abramsky, S., Gabbay, D. M., and Maibaum, T. S. E., (editors), Handbook of Logic in Computer Science, Volume 1, Oxford University Press, Oxford, 1992, 641-761

[20] Takahashi, W., Nonlinear Functional Analysis, Yakohama, 2000

DEPARTMENT OF Algebra

GEOMETRY AND TOPOLOGY

TIRASPOL STATE UNIVERSITY

5 GH. IABLOCIKIN, MD2069 CHIŞINĂU, REPUBLIC OF MOLDOVA

E-mail address: mmchoban@gmail.com

\footnotetext{
* Dedicated to Professor Emeritus Constantin Corduneanu on the occasion of his 85th birthday

Received: 01.10.2013; In revised form: 15.10.2013; Accepted: 18.10.2013

2010 Mathematics Subject Classification. 54H25, 54E15, 54H13, 12J17, 54E40.
}

Key words and phrases. Perfect pseudometric, quasi-perfect pseudometric, sequentially complete pseudometric, fixed point, ordered set, m-scale, Banach scale. 